\title{
Iterative Methods for Variational Inequalities over the Intersection of the Fixed Points Set of a Nonexpansive Semigroup in Banach Spaces
}

\author{
Issa Mohamadi \\ Department of Mathematics, Islamic Azad University, Sanandaj Branch, Sanandaj 418, Kurdistan, Iran \\ Correspondence should be addressed to Issa Mohamadi, imohamadi@iausdj.ac.ir \\ Received 8 November 2010; Accepted 19 November 2010 \\ Academic Editor: Qamrul Hasan Ansari \\ Copyright (c) 2011 Issa Mohamadi. This is an open access article distributed under the Creative \\ Commons Attribution License, which permits unrestricted use, distribution, and reproduction in \\ any medium, provided the original work is properly cited. \\ This paper presents a framework of iterative methods for finding specific common fixed points of a \\ nonexpansive self-mappings semigroup in a Banach space. We prove, with appropriate conditions, \\ the strong convergence to the solution of some variational inequalities.
}

\section{Introduction}

Let $C$ be a nonempty closed convex subset of a Hilbert space $H$, and let $F: C \rightarrow H$ be a nonlinear map. The classical variational inequality which is denoted by $\operatorname{VI}(F, C)$ is formulated as finding $x^{*} \in C$ such that

$$
\left\langle F x^{*}, x-x^{*}\right\rangle \geq 0
$$

for all $x \in C$. We recall that $F$ is called $\eta$-strongly monotone, if for each $x, y \in C$, we have

$$
\langle F x-F y, x-y\rangle \geq \eta\|x-y\|^{2},
$$

for a constant $\eta>0$, and also $\mathcal{\kappa}$-Lipschitzian if for each $x, y \in C$, we have

$$
\|F x-F y\| \leq \kappa\|x-y\|,
$$


for a constant $\kappa>0$. Existence and uniqueness of solutions are important problems of the $\operatorname{VI}(F, C)$. It is known that if $F$ is a strongly monotone and Lipschitzian mapping on $C$, then $\operatorname{VI}(F, C)$ has a unique solution. An important problem is how to find a solution of $\operatorname{VI}(F, C)$. It is known that

$$
x^{*} \in \mathrm{VI}(F, C) \Longleftrightarrow x^{*}=P_{C}\left(x^{*}-\lambda F x^{*}\right),
$$

where $\lambda>0$ is an arbitrarily fixed constant and $P_{C}$ is the projection of $H$ onto $C$. This alternative equivalence has been used to study the existence theory of the solution and to develop several iterative type algorithms for solving variational inequalities. But the fixed point formulation in (1.4) involves the projection $P_{C}$, which may not be easy to compute, due to the complexity of the convex set $C$. So, projection methods and their variant forms can be implemented for solving variational inequalities.

In order to reduce the complexity probably caused by the projection $P_{C}$, Yamada [1] (see also [2]) introduced a hybrid steepest-descent method for solving $\operatorname{VI}(F, C)$. His idea is stated now. Assume that $C$ is the fixed point set of a nonexpansive mapping $T: H \rightarrow H$. Recall that $T$ is nonexpansive if

$$
\|T x-T y\| \leq\|x-y\|, \quad \forall x, y \in H .
$$

Assume that $F$ is $\eta$-strongly monotone and $\kappa$-Lipschitzian on $C$. Take a fixed number $\mu \in$ $\left(0,2 \eta / \kappa^{2}\right)$ and a sequence $\left\{\lambda_{n}\right\}$ in $(0,1)$ satisfying the following conditions:

(C1) $\lim _{n \rightarrow \infty} \lambda_{n}=0$,

(C2) $\sum_{n=1}^{\infty} \lambda_{n}=\infty$,

(C3) $\lim _{n \rightarrow \infty}\left(\lambda_{n}-\lambda_{n+1}\right) / \lambda_{n+1}^{2}=0$.

Starting with an arbitrary initial guess $x_{0} \in H$, generate a sequence $\left\{x_{n}\right\}$ by the following algorithm:

$$
x_{n+1}:=T x_{n}-\lambda_{n+1} \mu F\left(T x_{n}\right), \quad n \geq 0 .
$$

Yamada [1] proved that the sequence $\left\{x_{n}\right\}$ converges strongly to a unique solution of $\operatorname{VI}(F, C)$. $\mathrm{Xu}$ and Kim [3] further considered and studied the hybrid steepest-descent algorithm (1.6). Their major contribution is that the strong convergence of (1.6) holds with condition (C3) being replaced by the following condition:

(C3) $\lim _{n \rightarrow \infty}\left(\lambda_{n}-\lambda_{n+1}\right) / \lambda_{n+1}=0$.

It is clear that condition (C3)' is strictly weaker than condition (C3), coupled with conditions $(C 1)$ and $(C 2)$. Moreover, $(C 3)^{\prime}$ includes the important and natural choice $\{1 / n\}$ for $\left\{\lambda_{n}\right\}$ whereas $(C 3)$ does not. For more related results, see $[4,5]$.

Let $X$ be a Banach space we recall that a nonexpansive semigroup is a family $\{T(t)$ : $t>0\}$ of self-mappings of $X$ satisfies the following conditions:

(i) $T(0) x=x$ for $x \in X$,

(ii) $T(t+s) x=T(t) T(s) x$ for $t, s>0$ and $x \in X$, 
Fixed Point Theory and Applications

(iii) $\lim _{t \rightarrow 0} T(t) x=x$ for $x \in X$,

(iv) for each $t>0, T(t)$ is nonexpansive. that is,

$$
\|T(t) x-T(t) y\| \leq\|x-y\|, \quad \forall x, y \in X
$$

The problem is to find some fixed point in $C=\bigcap_{t>0} \operatorname{Fix}(T(t))$. For this, so many algorithms have been developed and under some restrictions partial answers have been obtained [6-11].

Assume that $F: X \rightarrow X$ is a strongly monotone and Lipschitzian mapping and $\{T(t)$ : $t>0\}$ is a nonexpansive semigroup of self-mappings on $X$. For an appropriate $\mu$ and starting from an arbitrary initial point $x_{0} \in X$, we devise the following implicit, explicit, and modified iterations:

$$
\begin{gathered}
x_{n}:=\lambda_{n} x_{n}+\left(1-\lambda_{n}\right) T\left(t_{n}\right) x_{n}-\lambda_{n} \mu F x_{n}, \\
x_{n+1}:=\lambda_{n} x_{n}+\left(1-\lambda_{n}\right) T\left(t_{n}\right) x_{n}-\lambda_{n} \mu F x_{n}, \\
x_{n+1}:=\lambda_{n} y_{n}+\left(1-\lambda_{n}\right) T\left(t_{n}\right) x_{n} \\
y_{n}:=\left(1-\mu_{n}\right) x_{n}+\mu_{n}\left(T\left(t_{n}\right)-F\right) x_{n},
\end{gathered}
$$

for $n \geq 1$. With some appropriate assumptions, we prove the strong convergence of (1.8), (1.9), and (1.10) to the unique solution of the variational inequality $\left\langle F x^{*}, J\left(x-x^{*}\right)\right\rangle \geq 0$ in $C$, where $J$ is the single-valued normalized duality mapping from $X$ into $2^{X^{*}}$.

Our main purpose is to improve some of the conditions and results in the mentioned papers, especially those of Song and $\mathrm{Xu}[11]$.

\section{Preliminaries}

Let $S:=\{x \in X:\|x\|=1\}$ be the unit sphere of the Banach space $X$. The space $X$ is said to have Gateaux differentiable norm (or $X$ is said to be smooth), if the limit

$$
\lim _{t \rightarrow 0} \frac{\|x+t y\|-\|x\|}{t}
$$

exists for each $x, y \in S$, and $X$ is said to have a uniformly Gateaux differentiable norm if for each $y \in S$, the limit (2.1) converges uniformly for $x \in S$. Further, $X$ is said to be uniformly smooth if the limit (2.1) exists uniformly for $(x, y) \in S \times S$.

We denote $J$ the normalized duality mapping from $X$ to $2^{X^{*}}$ defined by

$$
J(x)=\left\{f^{*}:\left\langle x, f^{*}\right\rangle=\|x\|^{2}=\|f\|^{* 2}\right\}, \quad \forall x \in X .
$$

where $\langle\cdot, \cdot\rangle$ denotes the generalized duality pairing. It is well known if $X$ is smooth then any duality mapping on $X$ is single valued, and if $X$ has a uniformly Gateaux differentiable norm, then the duality mapping is norm to weak* uniformly continuous on bounded sets. 
Recall that a Banach space $X$ is said to be strictly convex if $\|x\|=\|y\|=1$ and $x \neq y$ implies $\|x+y\| / 2<1$. In a strictly convex Banach space $X$, we have that if $\|\lambda x+(1-\lambda) y\|=1$ for $\lambda \in(0,1)$ and $x, y \in X$, then $x=y$.

Now, we recall the concept of uniformly asymptotically regular semigroup. A continuous operator semigroup $\{T(t): t>0\}$ on $X$ is said to be uniformly asymptotically regular on $X$ if for all $h>0$ and any bounded subset $D$ of $X$, we have

$$
\lim _{t \rightarrow \infty} \sup _{x \in D}\|T(h)(T(t) x)-T(t) x\|=0 .
$$

The nonexpansive semigroup $\left\{\sigma_{t}(x)=(1 / t) \int_{0}^{t} T(s) x d s: t>0\right\}$ is an example of uniformly asymptotically regular operator semigroup [11].

Let $\mu$ be a continuous linear functional on $l^{\infty}$ satisfying $\|\mu\|=1=\mu(1)$. Then, we know that $\mu$ is a mean on $\mathbb{N}$ if and only if

$$
\inf \left\{a_{n}: n \in \mathbb{N}\right\} \leq \mu(a) \leq \sup \left\{a_{n}: n \in \mathbb{N}\right\},
$$

for every $a=\left(a_{1}, a_{2}, \ldots\right) \in l^{\infty}$. Sometimes, we use $\mu_{n}\left(a_{n}\right)$ instead of $\mu(a)$. A mean $\mu$ on $\mathbb{N}$ is called $a$ Banach limit if $\mu_{n}\left(a_{n}\right)=\mu_{n}\left(a_{n+1}\right)$. We know that if $\mu$ is a Banach limit, then

$$
\liminf _{n \rightarrow \infty} a_{n} \leq \mu(a) \leq \limsup _{n \rightarrow \infty} a_{n}
$$

for every $a=\left(a_{1}, a_{2}, \ldots\right) \in l^{\infty}$. Thus, if $a_{n} \rightarrow c$ as $n \rightarrow \infty$, then we have

$$
\mu_{n}\left(a_{n}\right)=\mu(a)=c
$$

A discussion on these and related concepts can be found in [12].

We make use of the following well-known results throughout the paper.

Lemma 2.1 (see [12, Lemma 4.5.4]). Let $D$ be a nonempty closed convex subset of a Banach space $X$ with a uniformly Gateaux differentiable norm, and let $\left\{y_{n}\right\}$ be a bounded sequence in $X$. If $z_{0} \in D$, then

$$
\mu_{n}\left\|y_{n}-z_{0}\right\|^{2}=\min _{y \in D} \mu_{n}\left\|y_{n}-y\right\|^{2}
$$

if and only if

$$
\mu_{n}\left\langle y-z_{0}, J\left(y_{n}-z_{0}\right)\right\rangle \leq 0
$$

for all $y \in D$.

Lemma 2.2 (see [13]). Let $\left\{s_{n}\right\},\left\{c_{n}\right\} \subset \mathbb{R}^{+},\left\{a_{n}\right\} \subset(0,1)$, and let $\left\{b_{n}\right\} \subset \mathbb{R}$ be sequences such that

$$
s_{n+1} \leq\left(1-a_{n}\right) s_{n}+b_{n}+c_{n}
$$


for all $n \geq 0$. Assume also that $\sum_{n \geq 0}\left|c_{n}\right|<\infty$. Then, the following results hold:

(i) if $b_{n} \leq \beta a_{n}$ (where $\beta \geq 0$ ), then $\left\{s_{n}\right\}$ is bounded,

(ii) if we have

$$
\sum_{n \geq 0} a_{n}=\infty, \quad \limsup _{n \rightarrow \infty} \frac{b_{n}}{a_{n}} \leq 0,
$$

then $\lim _{n \rightarrow \infty} s_{n}=0$.

Lemma 2.3. Let $X$ be a real normed linear space, and let $J$ be the normalized duality mapping on $X$. Then, for any $x, y \in X$, and $j \in J$, the following inequality holds:

$$
\|x+y\|^{2} \leq\|x\|^{2}+2\langle y, j(x+y)\rangle \text {. }
$$

In order to reduce any possible complexity in writing, we set $C=\bigcap_{t>0} \operatorname{Fix}(T(t))$ for a nonexpansive semigroup $\{T(t): t>0\}$ and

$$
D\left(x_{n}\right)=\left\{x \in X: g(x)=\inf _{y \in X} g(y)\right\}
$$

where $g(x)=\mu_{n}\left\|x_{n}-x\right\|^{2}$, for all $x \in X$, and $\left\{x_{n}\right\}$ is a bounded sequence in $X$.

\section{Implicit Iterative Method}

Recall that if $J$ is the single-valued normalized duality mapping from a Banach space $X$ into $2^{X^{*}}$, a nonlinear operator $F: X \rightarrow X$ is called $\eta$-strongly monotone if for every $x, y \in X$, the following inequality holds:

$$
\langle F x-F y, J(x-y)\rangle \geq \eta\|x-y\|^{2},
$$

for a constant $\eta>0$.

The following lemma will be be used to show the convergence of (1.8) and (1.9).

Lemma 3.1. Let $X$ be a Banach space, and let $J$ be the single-valued normalized duality mapping from $X$ into $2^{X^{*}}$. Assume also that $F: X \rightarrow X$ is $\eta$-strongly monotone and $\kappa$-Lipschitzian on $X$. Then,

$$
\psi(x)=I(x)-\mu F(x)
$$

is a contraction on $X$ for every $\mu \in\left(0, \eta / \kappa^{2}\right)$. 
Proof. By using Lemma 2.3, we have

$$
\begin{aligned}
\|\psi x-\psi y\|^{2} & \leq\|(I-\mu F) x-(I-\mu F) y\|^{2} \\
& =\|(x-y)+\mu(F y-F x)\|^{2} \\
& \leq\|x-y\|^{2}+2\langle\mu(F y-F x), J((x-y)+\mu(F y-F x))\rangle \\
& \leq\|x-y\|^{2}+2 \mu\langle F y-F x, J(x-y)\rangle+2 \mu^{2}\langle F y-F x, J(F y-F x)\rangle \\
& \leq\|x-y\|^{2}-2 \mu\langle F x-F y, J(x-y)\rangle+2 \mu^{2}\|F y-F x\|\|J(F y-F x)\| \\
& \leq\|x-y\|^{2}-2 \mu \eta\|x-y\|^{2}+2 \mu^{2}\|F y-F x\|^{2} \\
& \leq\|x-y\|^{2}-2 \mu \eta\|x-y\|^{2}+2 \mu^{2} \kappa^{2}\|x-y\|^{2} \\
& \leq\left(1-2 \mu \eta+2 \mu^{2} \kappa^{2}\right)\|x-y\|^{2},
\end{aligned}
$$

Thus, we obtain

$$
\|\psi x-\psi y\| \leq \sqrt{1-2 \mu\left(\eta-\mu \kappa^{2}\right)}\|x-y\|
$$

and for $\mu \in\left(0, \eta / \kappa^{2}\right)$, we have $\sqrt{1-2 \mu\left(\eta-\mu \kappa^{2}\right)} \in(0,1)$. That is, $\psi$ is a contraction, and the proof is complete.

In the following theorem, which is the main result in this section, we establish the strong convergence of the sequence defined by (1.8).

Theorem 3.2. Let $X$ be a real Banach space with a uniformly Gateaux differentiable norm, and let $\{T(t): t>0\}$ be a nonexpansive semigroup from $X$ into itself. Let also $\left\{x_{n}\right\}$ defined by (1.8) satisfies the following condition:

$$
C \cap D\left(x_{n}\right) \neq \emptyset .
$$

Assume that $F: X \rightarrow X$ is $\eta$-strongly monotone and $\kappa$-Lipschitzian. Assume also that $\left\{t_{n}\right\}$ is a sequence of positive numbers that $\lim _{n \rightarrow \infty} t_{n}=\infty$ and $\left\{\lambda_{n}\right\} \subset(0,1)$. If $\mu \in\left(0, \eta / \kappa^{2}\right)$, then $\left\{x_{n}\right\}$ converges strongly to some fixed point $x^{*} \in C$, which is the unique solution in $C$ to the variational inequality $\operatorname{VI}^{*}(F, C)$, that is

$$
\left\langle F x^{*}, J\left(x-x^{*}\right)\right\rangle \geq 0, \quad \forall x \in C .
$$


Proof. We divide the proof into several steps.

Step 1. We first prove the uniqueness of the solution to $\operatorname{VI}^{*}(F, C)$; for this, we suppose $x^{*}, y^{*} \in$ $C$ are two solutions of $\operatorname{VI}^{*}(F, C)$. Thus, we have

$$
\begin{aligned}
& \left\langle F x^{*}, J\left(x^{*}-y^{*}\right)\right\rangle \leq 0, \\
& \left\langle F y^{*}, J\left(y^{*}-x^{*}\right)\right\rangle \leq 0 .
\end{aligned}
$$

By adding up the last two inequalities, we obtain

$$
\eta\left\|x^{*}-y^{*}\right\|^{2} \leq\left\langle F x^{*}-F y^{*}, J\left(x^{*}-y^{*}\right)\right\rangle \leq 0,
$$

and so, $x^{*}=y^{*}$.

Step 2. We claim that $\left\{x_{n}\right\}$ is bounded. In fact, taking a fixed $x^{*} \in C$, we have

$$
\begin{aligned}
\left\|x_{n}-x^{*}\right\| & =\left\|\lambda_{n} x_{n}+\left(1-\lambda_{n}\right) T\left(t_{n}\right) x_{n}-\lambda_{n} \mu F x_{n}-x^{*}\right\| \\
& \leq \lambda_{n}\left\|x_{n}-\mu F x_{n}-x^{*}\right\|+\left(1-\lambda_{n}\right)\left\|T\left(t_{n}\right) x_{n}-x^{*}\right\| \\
& \leq \lambda_{n}\left\|(I-\mu F) x_{n}-(I-\mu F) x^{*}\right\|+\lambda_{n}\left\|(I-\mu F) x^{*}-x^{*}\right\|+\left(1-\lambda_{n}\right)\left\|x_{n}-x^{*}\right\| \\
& \leq \lambda_{n} \sqrt{1-2 \mu\left(\eta-\mu \kappa^{2}\right)}\left\|x_{n}-x^{*}\right\|+\left(1-\lambda_{n}\right)\left\|x_{n}-x^{*}\right\|+\lambda_{n} \mu\left\|F x^{*}\right\| \\
& \leq\left(1-\lambda_{n}\left(1-\sqrt{1-2 \mu\left(\eta-\mu \kappa^{2}\right)}\right)\right)\left\|x_{n}-x^{*}\right\|+\lambda_{n} \mu\left\|F x^{*}\right\| .
\end{aligned}
$$

Taking $\gamma=1-\sqrt{1-2 \mu\left(\eta-\mu \kappa^{2}\right)}$ and by using induction, we obtain

$$
\left\|x_{n}-x^{*}\right\| \leq \max \left\{\left\|x_{0}-x^{*}\right\|, \frac{\mu}{\gamma}\left\|F x^{*}\right\|\right\}
$$

therefore, $\left\{x_{n}-x^{*}\right\}$ is bounded and so is $\left\{x_{n}\right\}$.

Step 3. The sequence $\left\{x_{n}\right\}$ is sequentially compact. To prove this, we assume that the set $D\left(x_{n}\right)$ contains some $x^{*}$ such that $T(t) x^{*}=x^{*}$ for an arbitrary $t>0$. So, by using Lemma 2.1, we can obtain

$$
\mu_{n}\left\langle x-x^{*}, J\left(x_{n}-x^{*}\right)\right\rangle \leq 0, \quad \forall x \in X
$$

On the other hand, for any $q \in C$, we have

$$
\begin{aligned}
\left\|x_{n}-q\right\|^{2}= & \left\langle\lambda_{n}\left(x_{n}-q\right)+\left(1-\lambda_{n}\right)\left(T\left(t_{n}\right) x_{n}-q\right)-\mu \lambda_{n} F x_{n}, J\left(x_{n}-q\right)\right\rangle \\
\leq & \lambda_{n}\left\|(I-\mu F) x_{n}-(I-\mu F) q\right\|\left\|x_{n}-q\right\|+\lambda_{n}\left\langle-\mu F(q), J\left(x_{n}-q\right)\right\rangle \\
& +\left(1-\lambda_{n}\right)\left\langle T\left(t_{n}\right) x_{n}-T\left(t_{n}\right) q, J\left(x_{n}-q\right)\right\rangle \\
\leq & \left(1-\lambda_{n} \gamma\right)\left\|x_{n}-q\right\|^{2}+\lambda_{n}\left\langle-\mu F(q), J\left(x_{n}-q\right)\right\rangle .
\end{aligned}
$$


Thus,

$$
\left\|x_{n}-q\right\|^{2} \leq \frac{1}{\gamma}\left\langle(I-\mu F)(q)-q, J\left(x_{n}-q\right)\right\rangle \text {. }
$$

Also, we have

$$
\begin{aligned}
\left\|x_{n}-q\right\|^{2} & \leq \lambda_{n}\left\langle(I-\mu F) x_{n}-q, J\left(x_{n}-q\right)\right\rangle+\left(1-\lambda_{n}\right)\left\langle T\left(t_{n}\right) x_{n}-q, J\left(x_{n}-q\right)\right\rangle \\
& \leq \lambda_{n}\left\langle(I-\mu F) x_{n}-q, J\left(x_{n}-q\right)\right\rangle+\left(1-\lambda_{n}\right)\left\|x_{n}-q\right\|^{2} .
\end{aligned}
$$

It follows that

$$
\left\|x_{n}-q\right\|^{2} \leq\left\langle(I-\mu F) x_{n}-q, J\left(x_{n}-q\right)\right\rangle
$$

Combining (3.11) and (3.13) together, we get

$$
\mu_{n}\left\|x_{n}-x^{*}\right\|^{2} \leq \frac{\mu_{n}}{\gamma}\left\langle(I-\mu F)\left(x^{*}\right)-x^{*}, J\left(x_{n}-x^{*}\right)\right\rangle \leq 0 .
$$

This yields $\mu_{n}\left\|x_{n}-x^{*}\right\|=0$. Hence, there exists a subsequence of $\left\{x_{n}\right\}$ such as $\left\{x_{n_{k}}\right\}$ that converges strongly to $x^{*}$; that is, $\left\{x_{n}\right\}$ is sequentially compact.

Step 4. We claim that $x^{*}$ is the solution of $\operatorname{VI}^{*}(F, C)$. Since $\left\{x_{n}\right\}$ is bounded, for any fixed point $x \in C$, there exist a constant $L>0$ such that $\left\|x_{n}-x\right\| \leq L$. Therefore, we obtain

$$
\begin{aligned}
\left\|x_{n}-x\right\|^{2}= & \lambda_{n}\left\langle(I-\mu F) x_{n}-(I-\mu F) x^{*}, J\left(x_{n}-x\right)\right\rangle+\lambda_{n}\left\langle-\mu F x^{*}, J\left(x_{n}-x\right)\right\rangle \\
& +\left(1-\lambda_{n}\right)\left\langle T\left(t_{n}\right) x_{n}-T\left(t_{n}\right) x, J\left(x_{n}-x\right)\right\rangle+\lambda_{n}\left\langle x^{*}-x, J\left(x_{n}-x\right)\right\rangle \\
\leq & (2-\gamma) \lambda_{n} L\left\|x_{n}-x^{*}\right\|+\lambda_{n}\left\langle-\mu F x^{*}, J\left(x_{n}-x\right)\right\rangle+\left\|x_{n}-x\right\|^{2} .
\end{aligned}
$$

Hence,

$$
\left\langle F x^{*}, J\left(x_{n}-x\right)\right\rangle \leq \frac{L(2-\gamma)}{\mu}\left\|x_{n}-x^{*}\right\|
$$

Note that the duality mapping $J$ is single valued ( $X$ is smooth), and norm topology to weak* uniformly continuous on bounded sets of Banach space $X$ with uniformly Gateaux differentiable norm. Therefore,

$$
\left\langle F x^{*}, J\left(x_{n_{k}}-x\right)\right\rangle \longrightarrow\left\langle F x^{*}, J\left(x^{*}-x\right)\right\rangle,
$$

and by taking limit as $n_{k} \rightarrow \infty$ in two sides of (3.18), we obtain

$$
\left\langle F x^{*}, J\left(x^{*}-x\right)\right\rangle \leq 0, \quad \forall x \in C .
$$

Cosequently, $x^{*} \in C$ is the unique solution of $\operatorname{VI}^{*}(F, C)$. 
Step 5. $x_{n} \rightarrow x^{*}$ in norm. Indeed, we show that each cluster point of the sequence $\left\{x_{n}\right\}$ is equal to $x^{*}$. Assume that $y^{*}$ is another strong limit point of $\left\{x_{n}\right\}$ in $C$. Thanks to (3.15), we have the following two inequalities:

$$
\begin{aligned}
& \left\|x^{*}-y^{*}\right\|^{2} \leq\left\langle(I-\mu F)\left(x^{*}\right)-y^{*}, J\left(x^{*}-y^{*}\right)\right\rangle, \\
& \left\|y^{*}-x^{*}\right\|^{2} \leq\left\langle(I-\mu F)\left(y^{*}\right)-x^{*}, J\left(y^{*}-x^{*}\right)\right\rangle .
\end{aligned}
$$

Therefore,

$$
2\left\|x^{*}-y^{*}\right\|^{2} \leq\left\langle(I-\mu F)\left(x^{*}\right)-(I-\mu F) y^{*}+x^{*}-y^{*}, J\left(x^{*}-y^{*}\right)\right\rangle \leq(2-\gamma)\left\|x^{*}-y^{*}\right\|^{2} .
$$

It yields that $\left\|x^{*}-y^{*}\right\|^{2}=0$, which proves the uniqness of $x^{*}$. Thus, $\left\{x_{n}\right\}$ itself converges strongly to $x^{*}$. This completes the proof.

\section{Explicit Iterative Method}

In this section, we will present our result of the strong convergence of (1.9), but first, we need to prove, with different approach, the following lemma.

Lemma 4.1. Let $X,\{T(t): t>0\}, F,\left\{\lambda_{n}\right\},\left\{t_{n}\right\}, \mu$, and $\left\{x_{n}\right\}$ be as those in Theorem 3.2. If $x^{*}=$ $\lim _{n \rightarrow \infty} x_{n}$, and there exists a bounded sequence $\left\{y_{n}\right\}$ such that

$$
\lim _{n \rightarrow \infty}\left\|T(t) y_{n}-y_{n}\right\|=0, \quad \forall t>0
$$

Then,

$$
\limsup _{n \rightarrow \infty}\left\langle F x^{*}, J\left(x^{*}-y_{n}\right)\right\rangle \leq 0 .
$$

Proof. By the uniqueness of $x^{*}$ and with no loss of generality, we can choose $\lambda_{n}$ such that

$$
\lambda_{n} \longrightarrow 0, \quad \frac{\left\|T(t) y_{n}-y_{n}\right\|}{\lambda_{n}} \longrightarrow 0,
$$

as $n \rightarrow \infty$. Let $x_{\lambda_{n}}^{*}$ be the fixed point of the contraction

$$
\varphi_{\lambda_{n}}^{*}(x)=\lambda_{n} x+\left(1-\lambda_{n}\right) T\left(t_{n}\right) x-\lambda_{n} \mu F x, \quad x \in X .
$$


Then,

$$
x_{\lambda_{n}}^{*}-y_{n}=\lambda_{n}\left((I-\mu F) x_{\lambda_{n}}^{*}-y_{n}\right)+\left(1-\lambda_{n}\right)\left(T\left(t_{n}\right) x_{\lambda_{n}}^{*}-y_{n}\right)
$$

Now, by using Lemma 2.3, we have

$$
\begin{aligned}
\left\|x_{\lambda_{n}}^{*}-y_{n}\right\|^{2}= & \left(1-\lambda_{n}\right)^{2}\left\|T\left(t_{n}\right) x_{\lambda_{n}}^{*}-y_{n}\right\|^{2}+2 \lambda_{n}\left\langle(I-\mu F) x_{\lambda_{n}}^{*}-y_{n}, J\left(x_{\lambda_{n}}^{*}-y_{n}\right)\right\rangle \\
\leq & \left(1-\lambda_{n}\right)^{2}\left(\left\|T\left(t_{n}\right) x_{\lambda_{n}}^{*}-T\left(t_{n}\right) y_{n}\right\|+\left\|T\left(t_{n}\right) y_{n}-y_{n}\right\|\right)^{2}+2 \lambda_{n}\left\|x_{\lambda_{n}}^{*}-y_{n}\right\|^{2} \\
& +2 \lambda_{n}\left\langle-\mu F x_{\lambda_{n}}^{*} J\left(x_{\lambda_{n}}^{*}-y_{n}\right)\right\rangle \\
\leq & \left(1+\lambda_{n}^{2}\right)\left\|x_{\lambda_{n}}^{*}-y_{n}\right\|^{2}+\left\|T\left(t_{n}\right) y_{n}-y_{n}\right\|\left(2\left\|x_{\lambda_{n}}^{*}-y_{n}\right\|+\left\|T\left(t_{n}\right) y_{n}-y_{n}\right\|\right) \\
& +2 \lambda_{n}\left\langle-\mu F x_{\lambda_{n}}^{*} J\left(x_{\lambda_{n}}^{*}-y_{n}\right)\right\rangle .
\end{aligned}
$$

Therefore,

$$
\left\langle\mu F x_{\lambda_{n}^{\prime}}^{*} J\left(x_{\lambda_{n}}^{*}-y_{n}\right)\right\rangle \leq \frac{\lambda_{n}}{2}\left\|x_{\lambda_{n}}^{*}-y_{n}\right\|^{2}+\frac{\left\|T\left(t_{n}\right) y_{n}-y_{n}\right\|}{2 \lambda_{n}}\left(2\left\|x_{\lambda_{n}}^{*}-y_{n}\right\|+\left\|T\left(t_{n}\right) y_{n}-y_{n}\right\|\right) .
$$

Because $\left\{y_{n}\right\},\left\{T\left(t_{n}\right) y_{n}\right\}$ and $\left\{x_{\lambda_{n}}^{*}\right\}$ are bounded, from (4.3) and (4.7), we conclude that

$$
\limsup _{n \rightarrow \infty}\left\langle\mu F x_{\lambda_{n}}^{*} J\left(x_{\lambda_{n}}^{*}-y_{n}\right)\right\rangle \leq 0
$$

Moreover, we have

$$
\begin{aligned}
\left\langle\mu F x_{\lambda_{n}}^{*} J\left(x_{\lambda_{n}}^{*}-y_{n}\right)\right\rangle= & \left\langle x^{*}-(I-\mu F) x_{\lambda_{n}}^{*} J\left(x^{*}-y_{n}\right)\right\rangle+\left\langle x^{*}-(I-\mu F) x_{\lambda_{n}}^{*} J\left(x_{\lambda_{n}}^{*}-y_{n}\right)\right. \\
& \left.-J\left(x^{*}-y_{n}\right)\right\rangle+\left\langle x_{\lambda_{n}}^{*}-x^{*}, J\left(x_{\lambda_{n}}^{*}-y_{n}\right)\right\rangle .
\end{aligned}
$$

By Theorem 3.2, $x_{\lambda_{n}}^{*} \rightarrow x^{*}$, as $n \rightarrow \infty$. So, using the boundedness of $\left\{y_{n}\right\}$, we get

$$
\left\langle x_{\lambda_{n}}^{*}-x^{*}, J\left(x_{\lambda_{n}}^{*}-y_{n}\right)\right\rangle \rightarrow 0, \quad n \longrightarrow \infty
$$

On the other hand, noticing that the sequence $\left\{x_{\lambda_{n}}^{*}-y_{n}\right\}$ is bounded and the duality mapping $J$ is single-valued and norm to weak* uniformly continuous on bounded subsets of $X$, we conclude that

$$
\left\langle x^{*}-(I-\mu F) x_{\lambda_{n}}^{*} J\left(x_{\lambda_{n}}^{*}-y_{n}\right)-J\left(x^{*}-y_{n}\right)\right\rangle \longrightarrow 0, \quad n \longrightarrow \infty
$$


Fixed Point Theory and Applications

Therefore, from (4.8) and (4.9), we obtain

$$
\limsup _{n \rightarrow \infty}\left\langle F x^{*}, J\left(x^{*}-y_{n}\right)\right\rangle \leq 0
$$

This completes the proof.

Next, we prove the strong convergence of explicit iteration scheme (1.9).

Theorem 4.2. Let $X$ be a real Banach space with a uniformly Gateaux differentiable norm, and let $\{T(t): t>0\}$ be a nonexpansive semigroup from $X$ into itself. Let also $\left\{x_{n}\right\}$ defined by (1.9) satisfies the following conditions:

(i) $C \cap D\left(x_{n}\right) \neq \emptyset$,

(ii) $\lim _{n \rightarrow \infty}\left\|x_{n}-T(t) x_{n}\right\|=0$ for all $t>0$.

Assume that $F: X \rightarrow X$ is $\eta$-strongly monotone and $\kappa$-Lipschitzian, and that $\left\{t_{n}\right\}$ is a sequence of positive numbers that $\lim _{n \rightarrow \infty} t_{n}=\infty$. Assume also that the sequence $\left\{\lambda_{n}\right\}$ in $(0,1)$ satisfies the control condition

$$
\sum_{n=1}^{\infty} \lambda_{n}=\infty
$$

If $\mu \in\left(0, \eta / \kappa^{2}\right)$, then $\left\{x_{n}\right\}$ converges strongly to some fixed point $x^{*} \in C$, which is the unique solution in $C$ for the following variational inequality:

$$
\left\langle F x^{*}, J\left(x-x^{*}\right)\right\rangle \geq 0, \quad \forall x \in C .
$$

Proof. Existence and uniqueness of the solution of $\operatorname{VI}^{*}(F, C)$ is attained from Theorem 3.2. Now, we claim that $\left\{x_{n}\right\}$ is bounded. Indeed, taking a fixed $x^{*} \in C$, we have

$$
\begin{aligned}
\left\|x_{n+1}-x^{*}\right\| & =\left\|\lambda_{n} x_{n}+\left(1-\lambda_{n}\right) T\left(t_{n}\right) x_{n}-\lambda_{n} \mu F x_{n}-x^{*}\right\| \\
& \leq \lambda_{n}\left\|x_{n}-\mu F x_{n}-x^{*}\right\|+\left(1-\lambda_{n}\right)\left\|T\left(t_{n}\right) x_{n}-x^{*}\right\| \\
& \leq \lambda_{n}\left\|(I-\mu F) x_{n}-(I-\mu F) x^{*}\right\|+\lambda_{n}\left\|(I-\mu F) x^{*}-x^{*}\right\|+\left(1-\lambda_{n}\right)\left\|x_{n}-x^{*}\right\| \\
& \leq \lambda_{n} \sqrt{1-2 \mu\left(\eta-\mu \kappa^{2}\right)}\left\|x_{n}-x^{*}\right\|+\left(1-\lambda_{n}\right)\left\|x_{n}-x^{*}\right\|+\lambda_{n} \mu\left\|F x^{*}\right\| \\
& \leq\left(1-\lambda_{n}\left(1-\sqrt{1-2 \mu\left(\eta-\mu \kappa^{2}\right)}\right)\right)\left\|x_{n}-x^{*}\right\|+\lambda_{n} \mu\left\|F x^{*}\right\| .
\end{aligned}
$$

Taking $a_{n}=\lambda_{n}\left(1-\sqrt{1-2 \mu\left(\eta-\mu \kappa^{2}\right)}\right), b_{n}=\lambda_{n} \mu\left\|F x^{*}\right\|, c_{n}=0$, and using Lemma 2.2, we conclude that $\left\|x_{n}-x^{*}\right\|$ is bounded and so is $\left\|x_{n}\right\|$. 
Next, we prove that $\left\{x_{n}\right\}$ converges strongly to the unique solution $x^{*}$ of $\operatorname{VI}^{*}(F, C)$. By definition of the algorithm and taking $\gamma=1-\sqrt{1-2 \mu\left(\eta-\mu \kappa^{2}\right)}$, we have

$$
\begin{aligned}
\left\|x_{n+1}-x^{*}\right\|^{2}= & \lambda_{n}\left\langle(I-\mu F) x_{n}-x^{*}, J\left(x_{n+1}-x^{*}\right)\right\rangle+\left(1-\lambda_{n}\right)\left\langle T\left(t_{n}\right) x_{n}-x^{*}, J\left(x_{n+1}-x^{*}\right)\right\rangle \\
\leq & \lambda_{n}\left\langle(I-\mu F) x_{n}-(I-\mu F) x^{*}, J\left(x_{n+1}-x^{*}\right)\right\rangle+\lambda_{n}\left\langle-\mu F x^{*}, J\left(x_{n+1}-x^{*}\right)\right\rangle \\
& +\left(1-\lambda_{n}\right)\left\|T\left(t_{n}\right) x_{n}-x^{*}\right\|\left\|x_{n+1}-x^{*}\right\| \\
\leq & \mu \lambda_{n}\left\langle-F x^{*}, J\left(x_{n+1}-x^{*}\right)\right\rangle+\lambda_{n} \sqrt{1-2 \mu\left(\eta-\mu \kappa^{2}\right)}\left\|x_{n}-x^{*}\right\|\left\|x_{n+1}-x^{*}\right\| \\
& +\left(1-\lambda_{n}\right)\left\|x_{n}-x^{*}\right\|\left\|x_{n+1}-x^{*}\right\| \\
\leq & \mu \lambda_{n}\left\langle F x^{*}, J\left(x^{*}-x_{n+1}\right)\right\rangle+\lambda_{n} \sqrt{1-2 \mu\left(\eta-\mu \kappa^{2}\right)} \frac{\left\|x_{n}-x^{*}\right\|^{2}+\left\|x_{n+1}-x^{*}\right\|^{2}}{2} \\
& +\left(1-\lambda_{n}\right) \frac{\left\|x_{n}-x^{*}\right\|^{2}+\left\|x_{n+1}-x^{*}\right\|^{2}}{2} \\
\leq & \left(1-\lambda_{n} \gamma\right)\left\|x_{n}-x^{*}\right\|^{2}+2 \mu \lambda_{n}\left\langle F x^{*}, J\left(x^{*}-x_{n+1}\right)\right\rangle .
\end{aligned}
$$

Taking $a_{n}=\lambda_{n} \gamma, b_{n}=2 \mu \lambda_{n}\left\langle F x^{*}, J\left(x^{*}-x_{n+1}\right)\right\rangle$, and $c_{n}=0$ and using Lemma 4.1 together with Lemma 2.2 lead to $\lim _{n \rightarrow \infty}\left\|x_{n+1}-x^{*}\right\|^{2}=0$, that is, $x_{n} \rightarrow x^{*}$ in norm. This completes the proof.

Corollary 4.3. Let $X$ be a real reflexive strictly convex Banach space with a uniformly Gateaux differentiable norm. Let also $\{T(t): t>0\}$ be a nonexpansive semigroup from $X$ into itself such that $C=\bigcap_{t>0} \operatorname{Fix}(T(t)) \neq \emptyset$. Assume that $\left\{x_{n}\right\}$ defined by (1.9) satisfies condition (ii) in Theorem 4.2, then condition (i) holds.

Proof. Clearly, $g(x)=\mu_{n}\left\|x_{n}-x\right\|^{2}$ is a convex and continuous function. Because $X$ is a reflexive Banach space, according to [12, Theorem 1.3.11], $D\left(x_{n}\right)$ is nonempty. Also, by convexity and continuity of $g$, the set $D\left(x_{n}\right)$ is a closed convex subset of $X$. Since $\lim _{n \rightarrow \infty}\left\|T(t) x_{n}-x_{n}\right\|=0$ for every $x \in D\left(x_{n}\right)$ and $t>0$, we have

$$
g(T(t) x)=\mu_{n}\left\|x_{n}-T(t) x\right\|^{2}=\mu_{n}\left(\left\|x_{n}-T(t) x_{n}\right\|+\left\|T(t) x_{n}-T x\right\|\right)^{2} \leq \mu_{n}\left\|x_{n}-x\right\|^{2}=g(x) .
$$

So, $T(t) x \in D$, and therefore $T(t)\left(D\left(x_{n}\right)\right) \subset D\left(x_{n}\right)$. Suppose that $u \in C$. Because every nonempty closed convex subset of a strictly convex and reflexive Banach space $X$ is a Chebyshev set, according to [14, Corollary 5.1.19], there exists a unique $x^{*} \in D\left(x_{n}\right)$ such that

$$
\left\|u-x^{*}\right\|=\inf _{x \in D\left(x_{n}\right)}\|u-x\|
$$

On the other hand, $T(t) u=u$ for all $t>0, T(t) x^{*} \in D\left(x_{n}\right)$ and $T(t)$ is nonexpansive, so we get

$$
\left\|u-T(t) x^{*}\right\|=\left\|T(t) u-T(t) x^{*}\right\| \leq\left\|u-x^{*}\right\|,
$$


that is, $T(t) x^{*}=x^{*}$, by uniqueness of $x^{*} \in D\left(x_{n}\right)$. Thus, $x^{*} \in C \cap D\left(x_{n}\right)$. This completes the proof.

Corollary 4.4. Let $X$ be a real Banach space, and let $\{T(t): t>0\}$ be a nonexpansive uniformly asymptotically regular semigroup from $X$ into itself. If $\left\{x_{n}\right\}$ is defined by (1.9), where $\lambda_{n}$ satisfies (C1), then condition (ii) in Theorem 4.2 holds.

Proof. From (1.9), (C1), and the boundedness of $\left\{x_{n}\right\}$, we conclude that

$$
\left\|x_{n+1}-T\left(t_{n}\right) x_{n}\right\|=\lambda_{n}\left\|x_{n}-T\left(t_{n}\right) x_{n}-\mu F x_{n}\right\| \longrightarrow 0,
$$

as $n \rightarrow \infty$. On the other hand, the semigroup $\{T(t): t>0\}$ is uniformly asymptotically regular, $\lim _{n \rightarrow \infty} t_{n}=\infty$, and $S=\left\{x_{n}\right\}$ is a bounded subset in $X$, so for all $t>0$, we have

$$
\lim _{n \rightarrow \infty}\left\|T(t)\left(T\left(t_{n}\right) x_{n}\right)-T\left(t_{n}\right) x_{n}\right\| \leq \lim _{n \rightarrow \infty} \sup _{x \in S}\left\|T(t)\left(T\left(t_{n}\right) x\right)-T\left(t_{n}\right) x\right\|=0 .
$$

Hence,

$$
\begin{aligned}
\left\|x_{n+1}-T(t) x_{n+1}\right\| & \leq\left\|x_{n+1}-T\left(t_{n}\right) x_{n}\right\|+\left\|T\left(t_{n}\right) x_{n}-T(t)\left(T\left(t_{n}\right) x_{n}\right)\right\|+\left\|T(t)\left(T\left(t_{n}\right) x_{n}\right)-T(t) x_{n+1}\right\| \\
& \leq 2\left\|x_{n+1}-T\left(t_{n}\right) x_{n}\right\|+\left\|T(t)\left(T\left(t_{n}\right) x_{n}\right)-T\left(t_{n}\right) x_{n}\right\| .
\end{aligned}
$$

So, from (4.20), (4.21), and (4.22), we get

$$
\lim _{n \rightarrow \infty}\left\|x_{n}-T(t) x_{n}\right\|=0, \quad \forall t>0,
$$

and it completes the proof.

Remark 4.5. According to Corollaries 4.3 and 4.4, our assumptions are weaker than those of Song and $\mathrm{Xu}[11]$. Also, noticing that for a contraction $f: X \rightarrow X$, the mapping $(1 / \mu)(I-f)$ is strongly monotone and Lipschitzian. So, by replacing $(1 / \mu)(I-f)$ by $F$ in $(1.8)$ and (1.9), the following schemes are, respectively, obtained:

$$
\begin{gathered}
x_{n}:=\lambda_{n} f x_{n}+\left(1-\lambda_{n}\right) T\left(t_{n}\right) x_{n}, \\
x_{n+1}:=\lambda_{n} f x_{n}+\left(1-\lambda_{n}\right) T\left(t_{n}\right) x_{n} .
\end{gathered}
$$

Remark 4.6. In the same way and with the same conditions mentioned in Theorem 4.2, it's easy to see that the sequence $\left\{x_{n}\right\}$ defined by

$$
x_{n+1}:=T\left(t_{n}\right) x_{n}-\lambda_{n+1} \mu F\left(T\left(t_{n}\right) x_{n}\right), \quad n \geq 0
$$

converges strongly to the variational inequality $\operatorname{VI}^{*}(F, C)$. 


\section{Modified Iterative Method}

In this section, we show that the modified sequence $\left\{x_{n}\right\}$ defined by (1.10) also converges strongly to the solution of variational equality $\operatorname{VI}^{*}(F, C)$, but first, we need to prove the following lemma.

Lemma 5.1. Let $X$ be a Banach space. Assume that $F: X \rightarrow X$ is $\eta$-strongly monotone and $\mathcal{\kappa}$ Lipschitzian nonlinear operator and $T: X \rightarrow X$ a nonexpansive mapping. If $\mu \in\left(0, \eta / \sigma^{2}\right)$, where $\sigma=\kappa+2$, then

$$
\varphi(x)=I(x)-\mu(F+I-T)(x)
$$

is a contraction on $X$.

Proof. Considering the inequality

$$
\|x+y\|^{2} \leq\|x\|^{2}+2\langle y, J(x+y)\rangle,
$$

from Lemma 2.3 in a Banach space $X$, where $J: X \rightarrow 2^{X^{*}}$ is the normalized single-valued duality, we have

$$
\begin{aligned}
\|\varphi x-\varphi y\|^{2}= & \|(I-\mu(F+I-T)) x-(I-\mu(F+I-T)) y\|^{2} \\
= & \|(x-y)+\mu((F+I-T) y-(F+I-T) x)\|^{2} \\
\leq & \|x-y\|^{2}+2\langle\mu((F+I-T) y-(F+I-T) x), J((x-y) \\
& +\mu((F+I-T) y-(F+I-T) x))\rangle \\
\leq & \|x-y\|^{2}+2 \mu\langle(F+I-T) y-(F+I-T) x, J(x-y)\rangle+2 \mu^{2}\langle(F+I-T) y \\
& -(F+I-T) x, J((F+I-T) y-(F+I-T) x)\rangle \\
\leq & \|x-y\|^{2}-2 \mu\langle(F+I-T) x-(F+I-T) y, J(x-y)\rangle \\
& +2 \mu^{2}\|(F+I-T) y-(F+I-T) x\|\|J((F+I-T) y-(F+I-T) x)\| \\
\leq & \|x-y\|^{2}-2 \mu\langle F x-F y, J(x-y)\rangle-2 \mu\langle(I-T) x-(I-T) y, J(x-y)\rangle \\
& +2 \mu^{2}\|(F+I-T) y-(F+I-T) x\|\|J((F+I-T) y-(F+I-T) x)\| .
\end{aligned}
$$

Noticing that

$$
\langle(I-T) x,(I-T) y, J(x-y)\rangle \geq 0,
$$


we obtain

$$
\begin{aligned}
\|\varphi x-\varphi y\|^{2} & \leq\|x-y\|^{2}-2 \mu \eta\|x-y\|^{2}+2 \mu^{2}\|(F+I-T) y-(F+I-T) x\|^{2} \\
& \leq\|x-y\|^{2}-2 \mu \eta\|x-y\|^{2}+2 \mu^{2}(\kappa+2)^{2}\|x-y\|^{2} \\
& \leq\left(1-2 \mu \eta+2 \mu^{2} \sigma^{2}\right)\|x-y\|^{2} .
\end{aligned}
$$

Thus, we have

$$
\|\varphi x-\varphi y\| \leq \sqrt{1-2 \mu\left(\eta-\mu \sigma^{2}\right)}\|x-y\|
$$

Note that for $\mu \in\left(0, \eta / \sigma^{2}\right)$, we conclude $\sqrt{1-2 \mu\left(\eta-\mu \sigma^{2}\right)} \in(0,1)$. That is, $\varphi$ is a contraction and the proof is complete.

Theorem 5.2. Let $X$ be a real Banach space with a uniformly Gateaux differentiable norm and $\{T(t)$ : $t>0\}$ a nonexpansive semigroup from $X$ into itself. Let also $\left\{x_{n}\right\}$ defined by (1.10) satisfies the following conditions:

(i) $C \cap D\left(x_{n}\right) \neq \emptyset$,

(ii) $\lim _{n \rightarrow \infty}\left\|x_{n}-T(t) x_{n}\right\|=0$ for all $t>0$.

Assume that $F: X \rightarrow X$ is $\eta$-strongly monotone and $\kappa$-Lipschitzian and $\left\{t_{n}\right\}$ a sequence of positive numbers that $\lim _{n \rightarrow \infty} t_{n}=\infty$. Assume also that the sequences $\left\{\mu_{n}\right\} \subset\left(0, \eta /\left(1+\sigma^{2}\right)\right)$, where $\sigma=\kappa+2$, and $\left\{\lambda_{n}\right\}$ in $(0,1)$ satisfy the following control conditions:

$\left(C_{1}\right) \sum_{n=1}^{\infty} \lambda_{n}=\infty$,

$\left(C_{2}\right)\left\{\mu_{n}\right\}$ does not take 0 as it's limit point.

Then, $\left\{x_{n}\right\}$ converges strongly to some fixed point $x^{*} \in C$, which is the unique solution in $C$ for the variational inequality $\operatorname{VI}^{*}(F, C)$.

Proof. Existence and uniqueness of the solution of $\mathrm{VI}^{*}(F, C)$ is obtained from Theorem 3.2. We claim that $\left\{x_{n}\right\}$ is bounded. Indeed, taking a fixed $x^{*} \in C$, we have

$$
\begin{aligned}
\left\|x_{n+1}-x^{*}\right\|= & \left\|\lambda_{n} y_{n}+\left(1-\lambda_{n}\right) T\left(t_{n}\right) x_{n}-x^{*}\right\| \\
\leq & \lambda_{n}\left\|\left(I-\mu_{n}\left(F+I-T\left(t_{n}\right)\right)\right) x_{n}-x^{*}\right\|+\left(1-\lambda_{n}\right)\left\|T\left(t_{n}\right) x_{n}-x^{*}\right\| \\
\leq & \lambda_{n}\left\|\left(I-\mu_{n}\left(F+I-T\left(t_{n}\right)\right)\right) x_{n}-\left(I-\mu_{n}\left(F+I-T\left(t_{n}\right)\right)\right) x^{*}\right\| \\
& +\lambda_{n}\left\|\left(I-\mu_{n}\left(F+I-T\left(t_{n}\right)\right)\right) x^{*}-x^{*}\right\|+\left(1-\lambda_{n}\right)\left\|x_{n}-x^{*}\right\| \\
\leq & \lambda_{n} \sqrt{1-2 \mu_{n}\left(\eta-\mu_{n} \sigma^{2}\right)}\left\|x_{n}-x^{*}\right\|+\left(1-\lambda_{n}\right)\left\|x_{n}-x^{*}\right\|+\lambda_{n} \mu_{n}\left\|F x^{*}\right\| \\
\leq & \left(1-\lambda_{n}\left(1-\sqrt{1-2 \mu_{n}\left(\eta-\mu_{n} \sigma^{2}\right)}\right)\right)\left\|x_{n}-x^{*}\right\|+\lambda_{n} \mu_{n}\left\|F x^{*}\right\| .
\end{aligned}
$$


Noticing that

$$
\mu_{n}^{2}<1-\sqrt{1-2 \mu_{n}\left(\eta-\mu_{n} \sigma^{2}\right)}
$$

and by assumption that there exists $\epsilon>0$ so that $\mu_{n}>\epsilon$, for all $n \in N$. Thus, we get

$$
\left\|x_{n+1}-x^{*}\right\| \leq\left(1-\lambda_{n} \mu_{n}^{2}\right)\left\|x_{n}-x^{*}\right\|+\frac{1}{\epsilon} \lambda_{n} \mu_{n}^{2}\left\|F x^{*}\right\|,
$$

and from Lemma 2.2, we conclude that $\left\{x_{n}\right\}$ is bounded.

By Theorem 3.2, there exists a unique solution $x^{*}$ to $\operatorname{VI}^{*}(F, C)$. We prove that $\left\{x_{n}\right\}$ converges strongly to $x^{*}$

$$
\begin{aligned}
\left\|x_{n+1}-x^{*}\right\|^{2}= & \lambda_{n}\left\langle\left(I-\mu_{n}\left(F+I-T\left(t_{n}\right)\right)\right) x_{n}-x^{*}, J\left(x_{n+1}-x^{*}\right)\right\rangle \\
& +\left(1-\lambda_{n}\right)\left\langle T\left(t_{n}\right) x_{n}-x^{*}, J\left(x_{n+1}-x^{*}\right)\right\rangle \\
\leq & \lambda_{n}\left\langle\left(I-\mu_{n}\left(F+I-T\left(t_{n}\right)\right)\right) x_{n}-\left(I-\mu_{n}\left(F+I-T\left(t_{n}\right)\right)\right) x^{*}, J\left(x_{n+1}-x^{*}\right)\right\rangle \\
& +\lambda_{n}\left\langle-\mu_{n}\left(F+I-T\left(t_{n}\right)\right) x^{*}, J\left(x_{n+1}-x^{*}\right)\right\rangle+\left(1-\lambda_{n}\right)\left\|T\left(t_{n}\right) x_{n}-x^{*}\right\|\left\|x_{n+1}-x^{*}\right\| \\
\leq & \mu_{n} \lambda_{n}\left\langle-F x^{*}, J\left(x_{n+1}-x^{*}\right)\right\rangle+\lambda_{n} \sqrt{1-2 \mu_{n}\left(\eta-\mu_{n} \sigma^{2}\right)}\left\|x_{n}-x^{*}\right\|\left\|x_{n+1}-x^{*}\right\| \\
& +\left(1-\lambda_{n}\right)\left\|x_{n}-x^{*}\right\|\left\|x_{n+1}-x^{*}\right\| \\
\leq & \mu_{n} \lambda_{n}\left\langle F x^{*}, J\left(x^{*}-x_{n+1}\right)\right\rangle+\lambda_{n} \sqrt{1-2 \mu_{n}\left(\eta-\mu_{n} \sigma^{2}\right)} \frac{\left\|x_{n}-x^{*}\right\|^{2}+\left\|x_{n+1}-x^{*}\right\|^{2}}{2} \\
& +\left(1-\lambda_{n}\right) \frac{\left\|x_{n}-x^{*}\right\|^{2}+\left\|x_{n+1}-x^{*}\right\|^{2}}{2} \\
\leq & \left(1-\lambda_{n}\left(1-\sqrt{1-2 \mu_{n}\left(\eta-\mu_{n} \sigma^{2}\right)}\right)\right)\left\|x_{n}-x^{*}\right\|^{2}+2 \lambda_{n} \mu_{n}\left\langle F x^{*}, J\left(x^{*}-x_{n+1}\right)\right\rangle \\
\leq & \left(1-\lambda_{n} \mu_{n}^{2}\right)\left\|x_{n}-x^{*}\right\|^{2}+\frac{2 \lambda_{n} \mu_{n}^{2}}{\epsilon}\left\langle F x^{*}, J\left(x^{*}-x_{n+1}\right)\right\rangle .
\end{aligned}
$$

Taking $a_{n}=\lambda_{n} \mu_{n}^{2}, b_{n}=\left(2 \lambda_{n} \mu_{n}^{2} / \epsilon\right)\left\langle F x^{*}, J\left(x^{*}-x_{n+1}\right)\right\rangle$, and $c_{n}=0$ and using Lemma 4.1 together with Lemma 2.2 imply $\lim _{n \rightarrow \infty}\left\|x_{n+1}-x^{*}\right\|^{2}=0$, that is,

$$
\lim _{n \rightarrow \infty}\left\|x_{n}-x^{*}\right\|=0
$$

This completes the proof.

Remark 5.3. In Theorem 5.2, if $\eta>1$, then $\mu_{n}<1-\sqrt{1-2 \mu_{n}\left(\eta-\mu_{n} \sigma^{2}\right)}$, and therefore we can remove $\left(C_{2}\right)$, also $\left(C_{1}\right)$ turns to $\sum_{n=1}^{\infty} \lambda_{n} \mu_{n}=\infty$. 
Remark 5.4. We can easily see that under some restrictions all the strongly monotone and Lipschitzian nonlinear operators used in this paper are replaceable by strongly accretive and strictly pseudocontractive ones (see [15]).

\section{References}

[1] I. Yamada, "The hybrid steepest-descent method for the variational inequality problem of the intersection of fixed point sets of nonexpansive mappings," in Inherently Parallel Algorithm for Feasibility and Optimization, D. Butnariu, Y. Censor, and S. Reich, Eds., pp. 473-504, Elsevier, New York, NY, USA, 2001.

[2] F. Deutsch and I. Yamada, "Minimizing certain convex functions over the intersection of the fixed point sets of nonexpansive mappings," Numerical Functional Analysis and Optimization, vol. 19, no. 1-2, pp. 33-56, 1998.

[3] H. K. Xu and T. H. Kim, "Convergence of hybrid steepest-descent methods for variational inequalities," Journal of Optimization Theory and Applications, vol. 119, no. 1, pp. 185-201, 2003.

[4] H.-K. Xu, "Iterative algorithms for nonlinear operators," Journal of the London Mathematical Society, vol. 66, no. 1, pp. 240-256, 2002.

[5] S. Saeidi, "Modified hybrid steepest-descent methods for variational inequalities and fixed points," Mathematical and Computer Modelling, vol. 52, no. 1-2, pp. 134-142, 2010.

[6] N. Shioji and W. Takahashi, "Strong convergence of approximated sequences for nonexpansive mappings in Banach spaces," Proceedings of the American Mathematical Society, vol. 125, no. 12, pp. 3641-3645, 1997.

[7] N. Shioji and W. Takahashi, "Strong convergence theorems for asymptotically nonexpansive semigroups in Hilbert spaces," Nonlinear Analysis: Theory, Methods and Applications, vol. 34, no. 1, pp. 87-99, 1998.

[8] T. Suzuki, "On strong convergence to common fixed points of nonexpansive semigroups in Hilbert spaces," Proceedings of the American Mathematical Society, vol. 131, no. 7, pp. 2133-2136, 2003.

[9] H.-K. Xu, "A strong convergence theorem for contraction semigroups in Banach spaces," Bulletin of the Australian Mathematical Society, vol. 72, no. 3, pp. 371-379, 2005.

[10] R. Chen and Y. Song, "Convergence to common fixed point of nonexpansive semigroups," Journal of Computational and Applied Mathematics, vol. 200, no. 2, pp. 566-575, 2007.

[11] Y. Song and S. Xu, "Strong convergence theorems for nonexpansive semigroup in Banach spaces," Journal of Mathematical Analysis and Applications, vol. 338, no. 1, pp. 152-161, 2008.

[12] W. Takahashi, Nonlinear Functional Analysis: Fixed Point Theory and Its Applications, Yokohama Publishers, Yokohama, Japan, 2002.

[13] P.-E. Maingé, "Approximation methods for common fixed points of nonexpansive mappings in Hilbert spaces," Journal of Mathematical Analysis and Applications, vol. 325, no. 1, pp. 469-479, 2007.

[14] R. E. Megginson, An Introduction to Banach Space Theory, vol. 183 of Graduate Texts in Mathematics, Springer, New York, NY, USA, 1998.

[15] L.-C. Ceng, Q. H. Ansari, and J.-C. Yao, "Mann-type steepest-descent and modified hybrid steepestdescent methods for variational inequalities in Banach spaces," Numerical Functional Analysis and Optimization, vol. 29, no. 9-10, pp. 987-1033, 2008. 